\title{
Electroless Deposition of Ag Thin Films
}

\author{
Fionnuala Buckley* and Greg Hope ${ }^{\dagger}$ \\ School of Science \\ Griffith University, Brisbane, Queensland 4111 \\ *Email: Fionnuala.Buckley@student.griffith.edu.au \\ Telephone: (07) 373 53656, Fax: (07) 37357656 \\ †Email: g.hope@griffith.edu.au \\ Telephone: (07) 373 57550, Fax: (07) 37357656
}

\begin{abstract}
Silver thin films were deposited on glass with an electroless solution deposition technique, commonly known as the Tollen's test for aldehydes. The deposition process was investigated by using Raman spectroscopy and surface enhanced Raman scattering (SERS) where propionaldehyde was used as the reductant. Scanning electron microscopy was used to characterize the film morphology.
\end{abstract}

Keywords - Silver mirror; CBD; electroless; Raman; SERS.

\section{INTRODUCTION}

Surface deposition processes that take place during the deposition of semiconductor or metallic films from solution is an area known as chemical bath deposition (CBD) or alternatively, electroless deposition. Film formation commences with the deposition of nanoparticles onto a substrate surface and these particles then continue growing laterally to form the film. A thorough understanding of the chemistry of solution deposition processes of semiconductor and metallic films is required in order to design optimal thin films in a cost effective manner. This paper reports the SERS data obtained from growing silver metal films during the reduction of ammoniacal silver nitrate by propionaldehyde.

A well-known example of CBD is the Tollen's test for aldehydes and reducing sugars. In this chemical reaction, complexed silver ions react with an aldehyde or an oxidizable sugar (a 'reducing' sugar) to generate a silver deposit on a glass surface. The glass surface is prepared by soaking in nitric acid and then rinsing with water. Glass surfaces will then generate a uniform silver coating. CBD films can be deposited onto a wide range of surfaces with minimal preparation required other than this cleaning. Hydrophobic plastics, hydrophilic glass, metals and semiconductors can be coated with controllable mirror-like thin films of semiconductors or metallic deposits. In the case of silver metal deposition, changing the reducing agent chemistry can result in colloidal silver with the capacity to deposit a range of structures [1]. Silver mirrors have been used as surface-enhanced Raman-active substrates [2-4] in order to investigate the adsorption of organic molecules [5-7], but the process of mirror formation itself does not appear to have been investigated.

Reducing ammoniacal silver nitrate solution with propionaldehyde deposited a silver mirror on a glass substrate. Raman spectra were taken of the solution before addition of the aldehyde and of the glass - solution interface during the formation of the silver mirror deposit.

\section{EXPERIMENTAL METHODS}

Silver mirror. Silver mirrors were deposited on glass using the Tollen's test for identifying aldehydes, where propionaldehyde $\left(\mathrm{CH}_{3} \mathrm{CH}_{2} \mathrm{HO}\right)$ was used as the reductant. The aldehyde was obtained from Aldrich and used without further purification. All glassware was washed in $2 \mathrm{M} \mathrm{HNO}_{3}$, rinsed with deionised water and dried in air prior to use. Deposit morphology was investigated using three different methods:

Method 1. The following solutions were added to a glass vial in the following order: $4000 \mu \mathrm{L} 0.25 \mathrm{M} \mathrm{AgNO}_{3}, 3 \times 100 \mu \mathrm{L}$ aliquats of $0.1 \mathrm{M} \mathrm{NaOH}$ to form a fine brown precipitate of $\mathrm{Ag}_{2} \mathrm{O}, 3 \times 100 \mu \mathrm{L}$ aliquats of $0.05 \mathrm{M} \mathrm{NH}_{3}$ to completely dissolve the precipitate, $9 \times 100 \mu \mathrm{L} 0.25 \mathrm{M} \mathrm{AgNO}_{3}$ aliquats were added until the solution became pale brown/yellow. Various amounts of $0.0097 \mathrm{M} \mathrm{CH}_{3} \mathrm{CH}_{2} \mathrm{HO}$ were then added to the ammonical silver nitrate solution and a glass substrate was placed in the vial. After 1 hour the substrate was removed, rinsed with deionised water and dried in air.

Method 2. The following solutions were added to a glass vial in the following order: $4000 \mu \mathrm{L} 0.25 \mathrm{M} \mathrm{AgNO}_{3}, 3 \times 100 \mu \mathrm{L}$ aliquats of $0.1 \mathrm{M} \mathrm{NaOH}$ to form a fine brown precipitate of $\mathrm{Ag}_{2} \mathrm{O}, 3 \times 100 \mu \mathrm{L}$ aliquats of $0.05 \mathrm{M} \mathrm{NH}_{3}$ to completely dissolve the precipitate, $13 \times 100 \mu \mathrm{L} 0.1 \mathrm{M} \mathrm{NaOH}$ aliquats were added until the solution became pale brown/yellow. Various amounts of $0.0097 \mathrm{M} \mathrm{CH} \mathrm{CH}_{2} \mathrm{HO}$ were then added to the ammoniacal silver nitrate solution and a glass substrate was placed in the vial. After 1 hour the substrate was removed, rinsed with deionised water and dried in air.

Method 3. A glass substrate was placed at the bottom of a glass container. 3 aliquats of ammoniacal silver nitrate solution as prepared in methods 1 and 2 were placed on the substrate. Several aliquats of concentrated $\mathrm{CH}_{3} \mathrm{CH}_{2} \mathrm{HO}(97 \mathrm{M})$ were also placed beside but not on the substrate at the bottom of the container. The container was then sealed and the substrate removed after 1 hour to be rinsed with deionised water and dried in air.

Propionic acid was obtained from Ajax and used without further purification. Silver propionate was made by mixing the acid with $1 \% \mathrm{AgNO}_{3}$. 
Raman Spectroscopy and SERS. Raman and SERS studies were conducted on a Renishaw System 100 Raman spectrometer where the incident radiation was conveyed from a $\mathrm{HeNe}$ laser of $633 \mathrm{~nm}$ excitation. Power at the sample was $\sim 6$ $\mathrm{mW}$ with a laser spot size of $\sim 50 \mu \mathrm{m}$. Raman scattered light was detected with a Peltier-cooled charge coupled device (CCD) detector with spectral resolution $2 \mathrm{~cm}^{-1}$ and the light was focused with an ultra-long working distance x20 Olympus Plan FI lens with a numerical aperture of 0.4. Raman spectra were also collected on a Renishaw 2000 system Raman microprobe spectrometer that has a rotary encoded grating stage and an internal two stage Peltier cooled $\left(-70^{\circ} \mathrm{C}\right) \mathrm{CCD}$ detector with a spectral resolution of $1 \mathrm{~cm}^{-1}$. A $442 \mathrm{~nm} \mathrm{He}-\mathrm{Cd}$ laser was used as the excitation source. The laser power at the sample was in the range $0.5-10 \mathrm{~mW}$. Data was processed using GRAMS32 software (Galactic Industries, Salem, NH, USA). The laser beam was focused inside a glass vial for solution samples and focused on the inside surface of the vial for SERS studies.

Scanning Electron Microscopy. SEM images of the silver mirrors were obtained using an FEI Quanta 200 environmental scanning electron microscope (ESEM). Back scattered images were taken with the instrument in environmental or high vacuum mode using an accelerating voltage of $25 \mathrm{keV}$. Various magnifications and scanning areas were used.

\section{RESULTS AND DISCUSSION}

The normal Raman spectrum of propionaldehyde is presented in Figure 1, together with SERS spectra taken from a silver mirror depositing on glass after 2 minutes and 5 minutes of growth. In the SERS spectra a very strong band is observed at $879 \mathrm{~cm}^{-1}$ that appears during the initial deposition stage and then decreases in intensity over time. This band is attributed to the $\mathrm{C}-\mathrm{CH}_{3}$ stretch. The band at $1560 \mathrm{~cm}^{-1}$ was attributable to the $\mathrm{HOH}$ bending mode of water.

The SERS spectra arise from the formation of silver particles as the silver cations are reduced and the aldehyde is oxidized to the acid. Unreacted silver ions precipitate the propionate as the insoluble silver salt at the metal surface.

Figure 2 presents Raman spectra for the solid silver propionate, propionic acid, propionaldehyde and the SERS spectrum obtained after ten minutes of film growth. The $v_{\mathrm{s}^{-}}$ $\mathrm{CO}_{2}^{-}$group exhibits a strong band at $1400 \mathrm{~cm}^{-1}$ for the silver propionate, and weaker $\mathrm{v}_{\mathrm{a}}$ and $\mathrm{v}_{\mathrm{s}}$ bands at $1460 \mathrm{~cm}^{-1}$ and 1440$1420 \mathrm{~cm}^{-1}$ for the dimeric acid and aldehyde species respectively. The SERS spectra show tate formation of silver proprionate was occurring during silver mirror deposition.

The main Raman bands for the aldehyde and acid are assigned in Table 1. The strongest bands arise from methyl and methylene antisymmetric and symmetric $\mathrm{C}-\mathrm{H}$ stretches $\left(v_{\mathrm{a}}\right.$ $\mathrm{CH}_{3}, v_{\mathrm{a}} \mathrm{CH}_{3}, v_{\mathrm{s}} \mathrm{CH}_{2}, v_{\mathrm{s}} \mathrm{CH}_{2}$ ) and antisymmetric and symmetric anion stretches $\left(v_{\mathrm{a}}\right.$ and $\left.v_{\mathrm{s}} \mathrm{RCO}_{2}^{-}\right)$.

The Raman bands that appear in the range $1380-1150 \mathrm{~cm}^{-1}$ are due to methylene twisting vibrations, those between 1080$880 \mathrm{~cm}^{-1}$ are due to methylene rocking and $\mathrm{C}-\mathrm{C}$ stretches while those between $460-330 \mathrm{~cm}-1$ are due to $\mathrm{CCC}$ bending modes and C-C stretches [8].

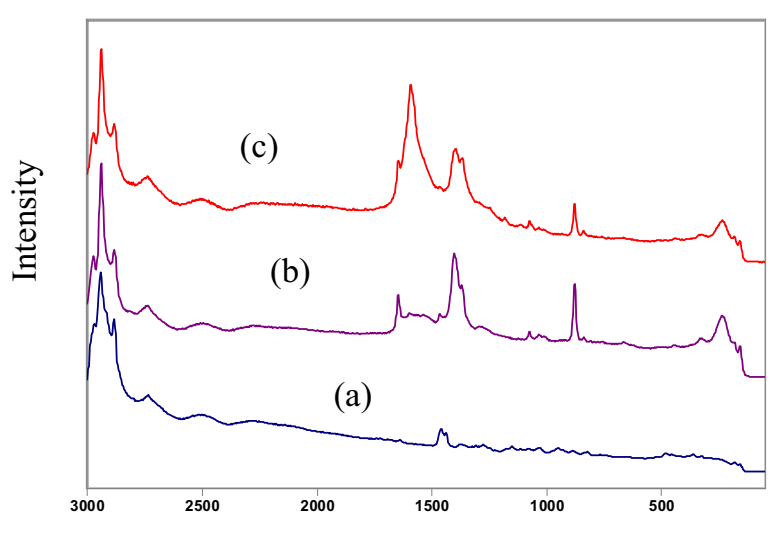

Raman shift $\left(\mathrm{cm}^{-1}\right)$

Figure 1. (a) Raman spectrum of propionaldehyde and SERS spectra of silver mirror on glass after (b) 2 min and (c) 5 min of growth.

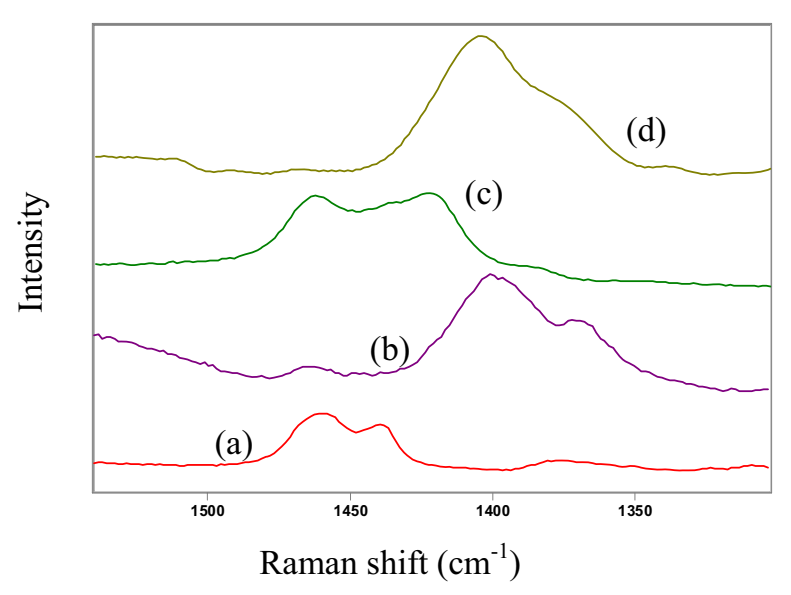

Figure 2. Raman spectra of (a) propionaldehyde; (b) SERS specrtrum of a silver mirror on glass after 10 minutes of growth; Raman spectrum of propionic acid; and (d) Raman spectrum of solid silver proponate.

The $\mathrm{C}-\mathrm{CH}_{3}$ stretch for propionic acid occurs at $845 \mathrm{~cm}^{-1}$ and is clearly lower than the corresponding band observed ( 879 $\mathrm{cm}^{-1}$ ) in the SERS spectra from Figure 1. The band shift to lower wavenumber is due to the acid existing as a dimer species. The fact that there is no Raman band attributed to $v \mathrm{C}$ $\mathrm{CH}_{3}$ observed in the spectrum for propionaldehyde demonstrates that this mode is enhanced by the presence of the large silver cation, enabling the alkyl chain $\mathrm{C}-\mathrm{C}$ stretch to be easily observed.

Figure 3 presents SEM micrographs of silver mirrors taken with the microscope in environmental mode (ESEM) and high vacuum mode (SEM). The environmental mode was used to help reduce charge buildup in the glass while the high vacuum mode was specifically used to obtain higher resolution images. 
TABLE I.

BAND ASSIGNMENTS

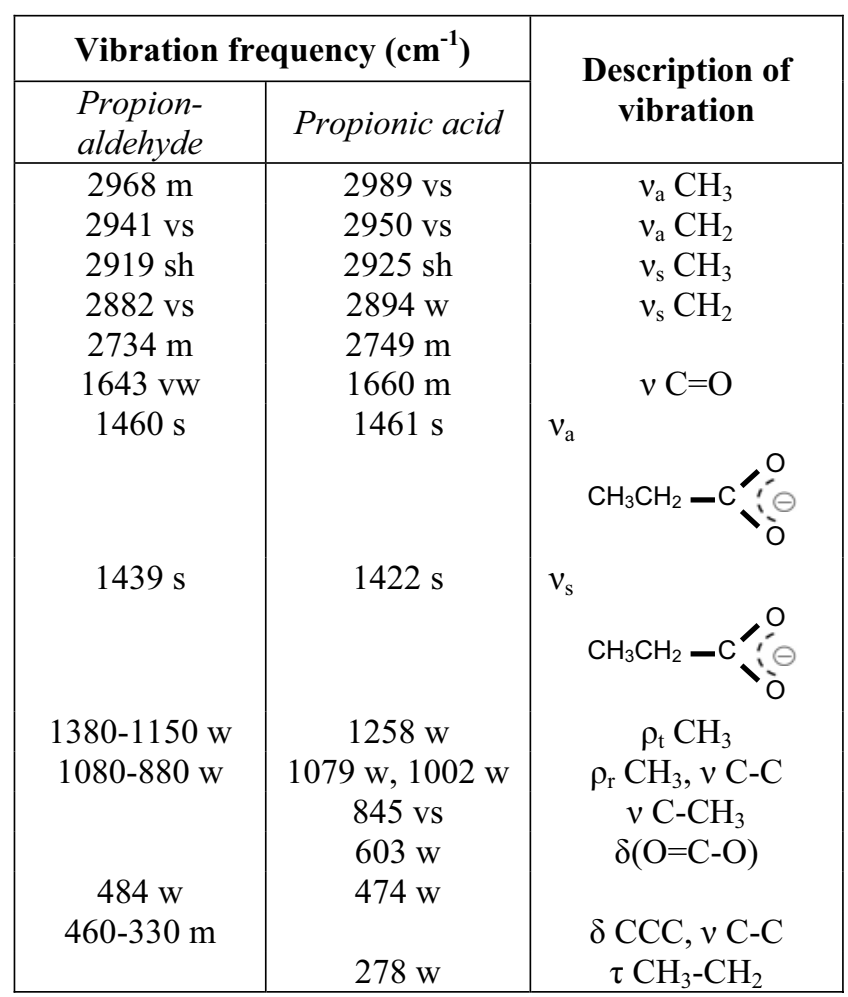

Silver mirror thin films deposited on glass using deposition methods 1, 2 and 3 (as outlined in the experimental section) were all composed of three different silver phases: (i) fine grained nanoparticles, (ii) larger string-like particles and clusters, and (iii) micron-sized crystals. The SEM micrograph in Figure 3(c) provides a good image of well formed octahedral silver crystals. The films are therefore not continuous but were rather formed by nanoparticles growing laterally on the glass substrate, which grow even larger to form the elongated particles and subsequently crystals. The amount of reducing agent, between $1600-2200 \mu \mathrm{L} 0.00097 \mathrm{M}$ propionaldehyde, had an effect on the amount of each phase present in the films. Generally, the amount of phase (ii) and (iii) increased with the volume of aldehyde used, and more of these two phases were yet again observed in films made from method 2 compared to method 1. This may have been due to the supply of aldehyde to the surface and therefore to the growth centers on the surface. The films produced using method 3 reacted very quickly and this would have been due to a combination of uniform vapour pressure and solubility. The film shown in Figure 3(b), made from method 3 using a silver ammonical solution from method 1, demonstrates that although a large amount of phase (i) and (ii) were present, the crystals were smaller.

The silver mirror shown in Figure 3(b) was later sonicated for 2 minutes in deionised water. After drying in air, the SEM micrograph taken from the film showed that the large silver crystals and a considerable amount of phase (ii) were removed after sonication.
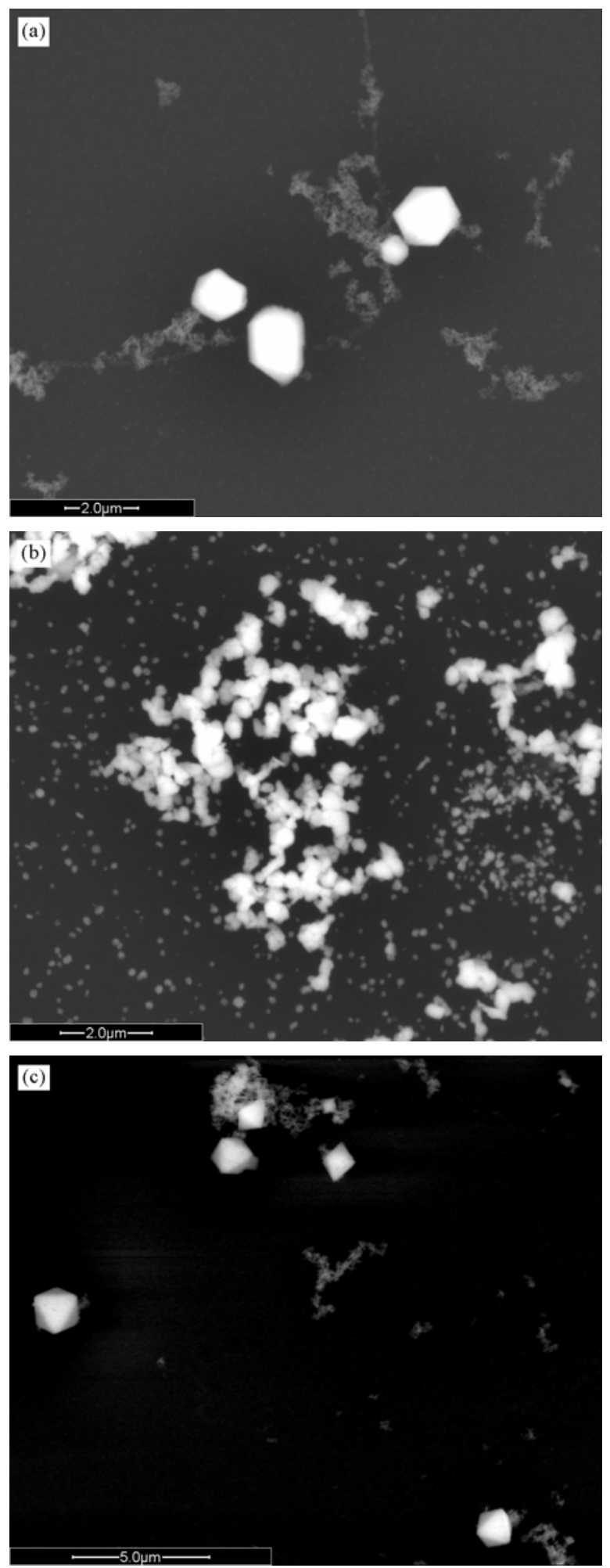

Figure 3. ESEM micrograph of silver mirrors as deposited using (a) method 1 with 1600 uL of propionaldehyde, (b) method 3 and SEM micrograph of octahedral silver crystals on surface of mirror (c), as deposited on glass using method 2 with $2200 \mu \mathrm{L}$ of propionaldehyde. 


\section{CONCLUSION}

The use of Raman spectroscopy and SERS are novel techniques with which to investigate the electroless deposition of silver thin films on glass. ESEM results show that the deposition technique produces fine grained particulate films. Propionate influences the structure of the silver deposit. ESEM investigations demonstrated that the silver film forms by first nucleating silver nanoparticles on the glass surface which then grow outwards. The fine grained films exhibited three distinct structures, fine nuclei on the glass, isolated strands of small crystals above these nuclei and a number of individual octahedral micron-sized single crystals distributed over the surface.

During the $\mathrm{Ag}^{+}$reduction process, SERS from aldehyde species was not observed. The Raman signal obtained was derived from silver propionate species enhanced on the depositing silver film. This indicates that the aldehyde species are oxidized in the solution at a distance from the silver deposit. Silver propionate is formed by reaction of the acid anion with silver cations and adsorbs onto the growing silver film surface.

\section{ACKNOWLEDGMENTS}

The authors thank Griffith University and the Australian Research Grants Scheme. The authors also thank Dr Thor Bostrom of the Analytical Electron Microscope Facility for access to and help with SEM instrumentation.

\section{REFERENCES}

[1] M. G. Albrecht, and J. A. Creighton, "Anomalously Intense Raman Spectra of Pyridine at a Silver Electrode" Journal of the American Chemical Society, vol. 99, pp. 5215, 1977.

[2] Y. Saito, J. J. Wang, D. A. Smith, and D. N. Batchelder, "A simple method for the preparation of silver surfaces for efficient SERS" Langmuir, vol. 18, pp. 2959-2961, 2002.

[3] J. Hu, B. Zhao, W. Xu, Y. Fan, B. Li, and Y. Ozaki, "Simple method for preparing controllably aggregated silver paricle films used as SERS active substrates" Langmuir, vol. 18, pp. 6839-6844, 2002.

[4] H. K. Park, J. K. Yoon, and K. Kim, "Novel Fabrication of Ag thin film on glass for efficient surface-enhanced Raman scattering" Langmuir, vol. 22, pp. 1626-1629, 2006.

[5] Y. Wu, B. Zhao, W. Xu, and B. Li, "Near-infrared SERS study of ultrathin films of azobenzene-containing long-chain fatty acids on a silver surface prepared by silver mirror and nitric acid etched silver foil methods" Langmuir, vol. 15, pp. 4625-4629, 1999.

[6] J. Hu, B. Zhao, W. Xu, B. Li, and Y. Fan, "Surface-enhanced Raman spectroscopy study on the structure changes of 4-mercaptopyridine adsorbed on silver substrates and silver colloids" Spectrochimica Acta Part A, vol. 58, pp. 2827-2834, 2002.

[7] W. Zhang, X. Ren, H. Li, J. Xie, C. Lu, Y. Zou, Z. Ni, and Q. Meng, "SERS from different azobenzene self-assembled monolayers and sandwiches" J. Coll. Int. Sci., vol. 268, pp. 173-180, 2003.

[8] F. R. Dollish, W. G. Fateley, F. F. Bentley, "Characteristic Raman frequenices of organic compounds", John Wiley \& Sons, New York, 1974. 